\title{
The COMT val158met Polymorphism Is Associated with Early Pubertal Development, Height and Cortical Bone Mass in Girls
}

\author{
ANNA-LENA ERIKSSON, MIIA SUURINIEMI, ANITTA MAHONEN, SULIN CHENG, AND \\ CLAES OHLSSON \\ Center for Bone Research at the Sahlgrenska Academy [A.-L.E., C.O.], Division of Clinical \\ Pharmacology, Department of Internal Medicine [A.-L.E., C.O.], Göteborg University, SE-413 45 \\ Göteborg, Sweden, Department of Health Sciences [M.S., S.C.], Department of Cell Biology [M.S.], \\ University of Jyväskylä, FIN-40014 Jyväskylä, Finland, Department of Medical Biochemistry [A.M.], \\ University of Kuopio, FIN-70211 Kuopio, Finland, The Calex-Study Research Group [A.-L.E., M.S., A.M.,
}

S.C., C.O.]

\begin{abstract}
Estrogens are involved in accretion of bone mass during puberty. Catechol-O-Methyltransferase (COMT) is involved in the degradation of estrogens. In this cross-sectional study we investigated associations between the COMT val158met polymorphism, which results in a 60-75\% difference in enzyme activity between the val (high activity $=\mathrm{H}$ ) and the met (low activity $=\mathrm{L}$ ) variant, and skeletal phenotypes in 246 healthy pre/early pubertal girls. Girls with $\mathrm{COMT}^{\mathrm{LL}}$ were $5.4 \mathrm{~cm}$ taller than $\mathrm{COMT}^{\mathrm{HH}}$ girls. Dual $\mathrm{x}$-ray absorptiometry showed higher values of bone mineral content (BMC), and larger areas of total body, femur and spine in COMT ${ }^{\mathrm{LL}}$. Cortical BMC, measured by peripheral quantitative computerized tomography in the tibia, was $9.8 \%$ higher in $\mathrm{COMT}^{\mathrm{LL}}$ compared with $\mathrm{COMT}^{\mathrm{HH}}$. This was due to a larger cortical cross sectional area while the cortical volumetric bone mineral density was not associated with COMT genotype. COMT ${ }^{\mathrm{LL}}$ girls had higher serum levels of free estradiol and insulin like growth factor. Regression models indicated that COMT genotype exerted effects on skeletal growth mainly via a regulation of free estradiol, resulting in an affected pubertal development (Tanner staging). We propose that the COMT ${ }^{\mathrm{LL}}$ genotype results in higher free estradiol levels and earlier pubertal development, leading to an increased skeletal growth in pre/early pubertal girls. Possible consequences for the adult
\end{abstract}

\section{ABSTRACT}

skeleton however can be determined only after cessation of growth. (Pediatr Res 58: 71-77, 2005)
Abbreviations
aBMD, areal bone mineral density
BMC, bone mineral content
BMD, bone mineral density
BMDvol, volume-corrected bone mineral density
BMI, body mass index
CE, catechol estrogen

COMT $^{\mathbf{H}}$, high-activity catechol-O-methyltransferase allele

COMT $^{\mathbf{L}}$, low-activity catechol-O-methyltransferase allele

CSA, cross-sectional area

DASH, dynamic allele specific hybridization

DXA, dual x-ray absorptiometry

ER, estrogen receptor

FTs, non-SHBG bound free testosterone

IGFBP-3, insulin-like growth factor binding protein 3

IRMA, immunoradiometric assay

pQCT, peripheral quantitative computerized tomography

SHBG, sex hormone binding globulin

vBMD, volumetric bone mineral density
Peak bone mineral density (BMD) is an important determinant of the risk of developing osteoporosis later in life $(1,2)$. It

Received June 1, 2004; accepted November 2, 2004.

Correspondence: Claes Ohlsson, M.D., Ph.D., Department of Internal Medicine, Division of Endocrinology, Gröna Stråket 8, 41345 Gothenburg, Sweden; e-mail: claes.

ohlsson@medic.gu.se

Supported by the Swedish Medical Research Council, the Swedish Foundation for Strategic Research, the European Commission, the Lundberg Foundation, the Torsten and Ragnar Söderberg's Foundation, the Emil and Vera Cornell Foundation, Petrus and Augusta Hedlunds Foundation, the Academy of Finland and Finnish Ministry of Education, Jyväskylä Toritutkain Medical Center, LIKES-Foundation for Sport and Health is generally well accepted that about $70 \%$ of the variation in peak BMD is due to genetic differences $(3,4)$. Several different hormones, growth factors and nutritional factors are involved in the regulation of the accretion of bone mass $(5,6)$. During childhood, thyroid hormones and the GH/IGF-axis are the principal hormones controlling growth (7-9). The following pubertal growth period is crucial for bone accretion, with past

Sciences, PEURUNKA-Medical Rehabilitation Center, Kuopio Hospital EVO Foundation, DelfiaT, Wallac Oy, Turku, Finland and the Novo Nordisk Foundation.

DOI: 10.1203/01.PDR.0000163383.49747.B5 
studies showing that BMD increases by $40-50 \%$ during this period $(8,10,11)$.

Estrogens are important regulators of pubertal bone accretion as they initiate the pubertal growth spurt and the final closure of the epiphyseal growth plates (12-15). Estrogens stimulate the secretion of growth hormone $(\mathrm{GH})(16,17)$, and GH in turn stimulates the production of IGF-I both locally in the bone and in the liver $(18-20)$. The effects of estrogens on bone accretion are thought to be exerted at least partly via this mechanism (10). Studies using genetically modified mouse models (8) as well as a clinical case report of a child with a disrupted IGF-I gene (21) have shown that IGF-I is of importance for bone accretion during sexual maturation. Apart from influencing the GH/IGF-I axis, estrogens may exert GH/IGF-I independent effects on skeletal growth and mineralization, supported by the fact that estrogen receptors (ERs) are expressed in growth plate cartilage and in osteoblasts (22-24).

The synthesis and metabolism of endogenous estrogens are mediated through complex metabolic pathways, involving several different enzymes. Estrogens are to a large extent metabolized by different isoenzymes of the cytochrome P450 family to catechol estrogens (CEs). The COMT gene codes for the Catechol-O-methyltransferase enzyme, which mediates the conversion of CEs to more inactive metabolites (25). Interestingly, there is a functional $\mathrm{G}$ to A polymorphism in the COMT gene. This results in a valine to methionine amino acid change at codon 158, differentiating the $\mathrm{COMT}^{\mathrm{H}}$ (high activity) and $\mathrm{COMT}^{\mathrm{L}}$ (low activity) alleles, which results in a 3-4 fold decreased methylation activity of the COMT enzyme (26). Thus, COMT ${ }^{\mathrm{LL}}$ homozygote individuals have a distinctly decreased COMT activity, resulting in less efficient inactivation of CE. We have previously shown that middle aged men with the $\mathrm{COMT}^{\mathrm{LL}}$ genotype have higher serum levels of estradiol than men with other genotypes (27).

The genetic factors responsible for the inter-individual differences in skeletal growth and mineralization during pubertal development are not well known. We hypothesized that the val158met polymorphism of the COMT gene, by regulating the degradation of estrogens, might influence the levels of estrogens and thereby affect growth and mineralization of the skeleton during puberty. We here demonstrate that the COMT polymorphism is associated with serum levels of free estradiol, height, cortical radial bone growth and early pubertal development in girls.

\section{MATERIALS AND METHODS}

Subjects. The subjects were 247 healthy girls residing in the city of Jyväskylä, Finland, and its surroundings, who were enrolled in an interventional study (the Calex study), to evaluate the effects of calcium, vitamin D, dairy products and physical activity on the acquisition of bone mass during pre/early puberty (28). The girls were $10-12$ y of age and in Tanner pubertal stages 1 or 2 when screened for enrollment. If there was disagreement between pubic hair and breast in Tanner staging, the final decision was made according to the development of the breasts. When returning for measurements, on average 3 mo after screening, 13 of the girls had progressed into Tanner stage 3. The investigational protocol was approved by the ethical committee of the University of Jyväskylä, the Central Hospital of Central Finland, and the Finnish National Agency of Medicines. An informed consent was obtained from all subjects and their parents before the assessments.

Anthropometrical measurements. Height and weight were determined with the subjects wearing light clothing only and no shoes. Height was determined using a fixed wall scale. Weight was determined within $0.5 \mathrm{~kg}$ for each subject using an electronic scale, calibrated before each measurement session. Body mass index (BMI) was calculated as weight $(\mathrm{kg}) /$ height $^{2}(\mathrm{~m})$. The length of the tibial shaft was determined using a measuring tape and based on a measurement between tuberositas tibia and the medial malleolus.

Dual $x$-ray absorptiometry (DXA). Bone area, bone mineral content (BMC), and areal bone mineral density (aBMD) of the whole body, femoral neck, femur trochanter, total femur and lumbar spine (L2-L4), as well as the lean soft tissue mass and fat mass of the whole body were assessed using the Lunar Prodigy DXA (GE Lunar Corp., Madison, WI USA). Sitting height was defined as the distance between the vertex and a line parallel to the lower edge of the tuber ischiadicum The coefficient of variation (CV\%) ranged from 0.60 to 1.18 for $\mathrm{BMC}, 0.86$ to 1.31 for $\mathrm{aBMD}$ and less than 1.1 for lean body mass, and 2.3 for fat mass. Volume-corrected BMD (BMDvol) of the L2-L4 vertebral bodies was calculated according to the formula $\mathrm{BMDvol}=\mathrm{BMC} / \mathrm{vol}=$ aBMD [4/( $\pi \times$ Width $)]$ (29).

Peripheral quantitative computerized tomography (pQCT). A pQCT device (XCT-2000, Stratec Medizintechnik, GmbH, Pforzheim, Germany) was used to scan the left tibial shaft and the distal radius. It was calibrated every day using a standard phantom and once a month using a cone phantom provided by the manufacturer. A $2 \mathrm{~mm}$ thick single tomographic slice was scanned with a voxel size of $0.59 \mathrm{~mm}$. The left tibial shaft was scanned in the transverse plane using the manufacturer's research mode at a site $60 \%$ of the way up the tibia. The lower leg length was measured when the subject was in a sitting position with a knee angle of $90^{\circ}$. The distal radius was scanned using the default mode at a site $4 \%$ of forearm length proximal to the growth plate according to standard operational procedures instructed by the manufacturer's protocol. The length of the forearm was defined as the distance from the olecranon to the ulna styloid with the elbow at $90^{\circ}$ and the forearm pronated. The cross sectional area $\left(\mathrm{CSA}, \mathrm{mm}^{2}\right)$, volumetric bone mineral density $\left(\mathrm{vBMD}, \mathrm{mg} / \mathrm{cm}^{3}\right)$, and polar moment of inertia $(\mathrm{g} * \mathrm{~mm})$ were analyzed using a validated software (BonAlyse 1.3, BonAlyse OY, Jyväskylä, Finland). On the basis of the vBMD calibration of the scan system used, $169 \mathrm{mg} / \mathrm{cm}^{3}$ and 280 $\mathrm{mg} / \mathrm{cm}^{3}$ were used as thresholds for the outer border of radius and tibia, respectively, and $100 \mathrm{mg} / \mathrm{cm}^{3}$ for the inner border of the tibia. We also used a high threshold of $711 \mathrm{mg} / \mathrm{cm}^{3}$ to specifically locate the cortical bone in the tibial shaft. The CVs were less than $1 \%$ for all pQCT measurements.

Laboratory assessments. Serum $17 \beta$-estradiol $\left(\mathrm{E}_{2}\right)$, testosterone $(\mathrm{T})$ and sex hormone binding globulin (SHBG) were assessed using a time-resolved fluoroimmunoassay (Delfia, Wallac Oy, Turku, Finland). The intra- and interassay $\mathrm{CV}$ s were $5.1 \%$ and $5.2 \%$ for $\mathrm{E}_{2}, 9.2 \%$ and $9.4 \%$ for $\mathrm{T}$ and $1.1 \%$ and $1.1 \%$ for SHBG respectively. NonSHBG bound free testosterone (FTs) was obtained using the following formula: proportion (\%) of FTs (FTs\%) = $2.28-1.38 * \log ($ SHBG nmol-1/10) and serum FTs $(\mathrm{pmol} / \mathrm{L})=\mathrm{FTs} \% * \mathrm{~T}$ $(\mathrm{nmol} / \mathrm{L}) * 10$. Free estradiol was calculated as: free estradiol $(\mathrm{pmol} / \mathrm{L})=\mathrm{E}_{2}$ $(\mathrm{pmol} / \mathrm{L}) /(\mathrm{K} \times \mathrm{SHBG}(\mathrm{nmol} / \mathrm{L})+1)$, with an equilibrium constant $(\mathrm{K})$ for SHBG of $0,68 \times 10^{9} \mathrm{~L} / \mathrm{mol}$ (30). Concentrations of serum growth hormone $(\mathrm{GH})$, IGF-I and IGF binding protein 3 (IGFBP-3) were measured using commercial immunoradiometric assays (IRMA) (Nichols Institute Diagnostics, San Juan Capistrano, California, USA). The intra-assay CVs for GH measurements ranged between 2.8 and 4.2, and inter-assay CVs were between 3.5 and 7.2. In IGF-1 assays, the intra-assay CVs were between 3.3 and 4.6 and inter-assay CVs ranged between 9.3 and 15.8. In IGFBP-3 assays the intraassay CVs were between 3.4 and 8.0 and inter-assay CVs ranged between 5.3 and 6.3 .

DNA isolation and genotyping. Genomic DNA was isolated from EDTAstabilized blood, using QIAamp Blood kit (Qiagen GmbH, Hilden, Germany). Amplification by polymerase chain reaction (PCR) was performed on a Multiblock System (Hybaid, Middlesex, UK) according to the manufacturers protocol (@Hybaid Limited march 20001.0 - Software Version 3.1). The forward and reverse primers for the COMT polymorphism were 5'AGTGGATGCTGGATTTCGCTG-3' and 5'-biotin-AGGCACGCACACCTTGTCCTT-3' respectively, and the annealing temperature was $54^{\circ}$. The COMT G-A polymorphism was genotyped using the dynamic allele specific hybridization (DASH) method (31). The following probes were used in the DASH analyses: 5'-TCGCTGGCGTGAAGGAC-3, which is specific for the high activity COMT allele and 5'-TCGCTGGCATGAAGGAC-3, which is specific for the low activity COMT allele.

Statistical analysis. All calculations were performed with the SPSS Statistical Software (version 10.0, SPSS, Chicago, IL). Continuous variables were compared between individuals with the different COMT-genotypes using analysis of variance (ANOVA). Categorical variables were compared using the Mantel Haenszel test. Regression analyses using free estradiol or muscle area as covariates were used to estimate the relative influence of COMT genotype and these variables on different skeletal parameters and Tanner stage. Bivariate correlations were calculated using Pearson's coefficient of correlations. The distributions of all variables were checked for normality. If the values of a 
variable were not normally distributed they were $\log$ transformed. All values are means $\pm \mathrm{SD}$. All tests were two tailed and conducted at $5 \%$ significance level.

\section{RESULTS}

COMT genotype. Genotyping for the COMT polymorphism was successful in 246/247 study subjects. 85 subjects (34.6\%) were homozygous for the low activity COMT allele $\left(\mathrm{COMT}^{\mathrm{LL}}\right), 118$ subjects $(48.0 \%)$ were heterozygous $\left(\mathrm{COMT}^{\mathrm{HL}}\right)$ and $43(17.5 \%)$ subjects were homozygous for the high activity COMT allele $\left(\mathrm{COMT}^{\mathrm{HH}}\right)$. The genotypes were in Hardy Weinberg equilibrium.

Height and body composition according to COMT genotype. Total height, sitting height and tibial shaft length of individuals with $\mathrm{COMT}^{\mathrm{LL}}$ were increased by $5.4 \mathrm{~cm}(3.8 \%), 3.0 \mathrm{~cm}$ $(4.0 \%)$ and $1.4 \mathrm{~cm}(4.0 \%)$ respectively, when compared with $\mathrm{COMT}^{\mathrm{HH}}$ individuals (Table 1). Individuals with $\mathrm{COMT}^{\mathrm{LL}}$ were also heavier than $\mathrm{COMT}^{\mathrm{HH}}$ individuals, but the associations between COMT genotype and weight were similar to the associations between COMT genotype and height, and did not result in statistically significant differences in BMI (Table 1). DXA measurements showed that the differences in weight were mainly due to larger amounts of lean body mass in $\mathrm{COMT}^{\mathrm{LL}}$, while only a tendency of an association with fat mass was seen $(p=0.10)$ (Table 1). pQCT measurements of the tibia showed a larger cross sectional muscle area in $\mathrm{COMT}^{\mathrm{LL}}$, indicating that the influence of the COMT polymorphism on lean body mass was to a large extent caused by a larger muscle mass. In contrast, cross sectional area of s.c. fat was not significantly associated with COMT genotype (Table 1).

DXA measurements of bone according to COMT genotype. Individuals with $\mathrm{COMT}^{\mathrm{LL}}$ had a total body BMC which was $12.7 \%$ higher than that of $\mathrm{COMT}^{\mathrm{HH}}$ (Table 2). When BMC of the lumbar spine, femoral neck, trochanter and total femur were analyzed separately a similar pattern was seen, though differences between genotypes did not reach statistical significance in the trochanter. Areas of total body, lumbar spine, femoral trochanter and total femur were larger in individuals with $\mathrm{COMT}^{\mathrm{LL}}$ compared with individuals with $\mathrm{COMT}^{\mathrm{HH}}$ (Table 2). There were no major associations between COMT genotype and the different aBMDs except for in the lumbar spine. However BMDvol at the spine did not differ between genotypes. This suggests that COMT genotype is mainly associated with skeletal size and not with volumetric BMD (Table 2).
pQCT measurements of cortical bone according to COMT genotype. $\mathrm{pQCT}$ measurements were performed to more in detail distinguish between effects on skeletal size and volumetric BMD. Measurements of cortical bone were performed in the tibia. Cortical BMC was $9.8 \%$ higher in $\mathrm{COMT}^{\mathrm{LL}}$ compared with $\mathrm{COMT}^{\mathrm{HH}}$ (Table 3). This was due to a larger cortical cross sectional area in $\mathrm{COMT}^{\mathrm{LL}}$, while the cortical vBMD did not differ between genotypes (Table 3). The periosteal circumference was wider in COMT ${ }^{\mathrm{LL}}$. The endosteal circumference was also wider in $\mathrm{COMT}^{\mathrm{LL}}$ but this difference was of a smaller magnitude than the difference in periosteal circumference and the net result was a wider cortical thickness (Table 3). Polar moment of inertia, which is an indicator of bone bending resistance was $19 \%$ higher in $\mathrm{COMT}^{\mathrm{LL}}$ compared with $\mathrm{COMT}^{\mathrm{HH}}$ (Table 3).

pQCT measurements of trabecular bone according to COMT genotype. No significant differences in trabecular vBMD of the distal radius were found between COMT genotypes $\left(225 \pm 31,226 \pm 29\right.$ and $222 \pm 21 \mathrm{mg} / \mathrm{cm}^{3}$ in COMT ${ }^{\mathrm{LL}}$, $\mathrm{COMT}^{\mathrm{HL}}$ and $\mathrm{COMT}^{\mathrm{HH}}$, respectively).

Hormone levels according to COMT genotype. Total serum levels of estradiol did not differ significantly when all three genotypes were compared (Table 4). When $\mathrm{COMT}^{\mathrm{LL}}$ and $\mathrm{COMT}^{\mathrm{HL}}$ were pooled into one single group however, the individuals with $\mathrm{COMT}^{\mathrm{HH}}$ had lower levels of estradiol than the other genotypes $(p=0.031)$. The levels of free estradiol were associated with COMT genotype, with $\mathrm{COMT}^{\mathrm{LL}}$ having higher levels than $\mathrm{COMT}^{\mathrm{HH}}$ (Table 4). Serum levels of testosterone were not associated with COMT genotype. There was a tendency of higher GH levels in $\mathrm{COMT}^{\mathrm{LL}}$ compared with $\mathrm{COMT}^{\mathrm{HL}}(110 \%$ over $\left.\mathrm{COMT}^{\mathrm{HH}}\right)$ and $\mathrm{COMT}^{\mathrm{HL}}\left(45 \%\right.$ over $\left.\mathrm{COMT}^{\mathrm{HL}}\right)$ respectively (Table 4). However, this difference did not reach statistical significance, probably due to large standard deviations as this hormone is secreted in a pulsatile fashion. Serum levels of IGF-I were increased in $\mathrm{COMT}^{\mathrm{LL}}$, but serum levels of IGFBP-3 were not associated with COMT genotype (Table 4). Serum levels of free estradiol and IGF-I were strongly correlated $(r=0.690, p<$ $0.001)$.

Interaction between the effects of COMT genotype and free estradiol. To further investigate the hypothesis that the increased skeletal growth seen in $\mathrm{COMT}^{\mathrm{LL}}$ is mediated via increased levels of estradiol, serum levels of free estradiol, were included together with COMT genotype as covariates in a regression model. Before adding free estradiol to the model,

Table 1. Weight and body composition according to COMT genotype

\begin{tabular}{|c|c|c|c|c|}
\hline Variable & $\operatorname{COMT}^{\mathrm{LL}}(n=85)$ & $\operatorname{COMT}^{\mathrm{HL}}(n=118)$ & $\mathrm{COMT}^{\mathrm{HH}}(n=43)$ & $p$ Value \\
\hline Age (y) & $11.3 \pm 0.8$ & $11.1 \pm 0.8$ & $11.1 \pm 0.6$ & NS \\
\hline Height $(\mathrm{cm})$ & $147.7 \pm 8.2$ & $145.3 \pm 8.0$ & $142.3 \pm 6.3$ & 0.001 \\
\hline Lower leg length $(\mathrm{cm})$ & $35.4 \pm 2.3$ & $34.6 \pm 2.5$ & $34.0 \pm 2.0$ & 0.004 \\
\hline Weight $(\mathrm{kg})$ & $40.6 \pm 8.4$ & $38.8 \pm 8.7$ & $35.9 \pm 6.7$ & 0.009 \\
\hline BMI $\left(\mathrm{kg} / \mathrm{m}^{2}\right)$ & $18.5 \pm 2.8$ & $18.2 \pm 3.0$ & $17.6 \pm 2.2$ & NS \\
\hline Total lean mass $(\mathrm{kg})$ & $28.1 \pm 4.4$ & $27.3 \pm 4.3$ & $25.5 \pm 3.0$ & 0.004 \\
\hline CSA subcutaneous fat $\left(\mathrm{mm}^{2}\right)$ & $2400 \pm 714$ & $2260 \pm 725$ & $2130 \pm 666$ & NS \\
\hline
\end{tabular}

Data are shown as mean $\pm \mathrm{SD}$. The $p$ values are for comparison of the three genotypes (one-way ANOVA). 
Table 2. DXA measurements of bone according to COMT genotype

\begin{tabular}{|c|c|c|c|c|}
\hline Variable & $\operatorname{COMT}^{\mathrm{LL}}(n=85)$ & $\operatorname{COMT}^{\mathrm{HL}}(n=118)$ & $\mathrm{COMT}^{\mathrm{HH}}(n=43)$ & $p$ Value \\
\hline BMC total body $(\mathrm{g})$ & $1470 \pm 275$ & $1403 \pm 276$ & $1304 \pm 216$ & 0.004 \\
\hline BMC spine L2-L4 (g) & $24.8 \pm 6.1$ & $23.2 \pm 5.6$ & $21.2 \pm 4.3$ & 0.003 \\
\hline BMC femur total (g) & $20.5 \pm 3.9$ & $20.3 \pm 4.0$ & $18.6 \pm 3.6$ & 0.032 \\
\hline BMC trochanter $(\mathrm{g})$ & $5.5 \pm 1.5$ & $5.3 \pm 1.7$ & $4.8 \pm 1.5$ & NS \\
\hline Area total body $\left(\mathrm{cm}^{2}\right)$ & $1533 \pm 215$ & $1473 \pm 218$ & $1397 \pm 171$ & 0.002 \\
\hline Area spine $\mathrm{L} 2-\mathrm{L} 4\left(\mathrm{~cm}^{2}\right)$ & $28.8 \pm 4.1$ & $27.9 \pm 3.8$ & $26.5 \pm 2.7$ & 0.005 \\
\hline Area trochanter $\left(\mathrm{cm}^{2}\right)$ & $7.9 \pm 1.6$ & $7.7 \pm 1.6$ & $7.2 \pm 1.4$ & 0.033 \\
\hline aBMD total body $\left(\mathrm{g} / \mathrm{cm}^{2}\right)$ & $0.95 \pm 0.06$ & $0.95 \pm 0.06$ & $0.93 \pm 0.06$ & NS \\
\hline aBMD spine $\mathrm{L} 2-\mathrm{L} 4\left(\mathrm{~g} / \mathrm{cm}^{2}\right)$ & $0.85 \pm 0.11$ & $0.82 \pm 0.10$ & $0.80 \pm 0.10$ & 0.013 \\
\hline BMDvol spine L2-L4 $\left(\mathrm{g} / \mathrm{cm}^{3}\right)$ & $0.32 \pm 0.03$ & $0.31 \pm 0.03$ & $0.31 \pm 0.04$ & NS \\
\hline aBMD femur total $\left(\mathrm{g} / \mathrm{cm}^{2}\right)$ & $0.84 \pm 0.09$ & $0.84 \pm 0.09$ & $0.81 \pm 0.09$ & NS \\
\hline aBMD femur neck $\left(\mathrm{g} / \mathrm{cm}^{2}\right)$ & $0.82 \pm 0.09$ & $0.82 \pm 0.09$ & $0.79 \pm 0.08$ & NS \\
\hline
\end{tabular}

Data are shown as mean $\pm \mathrm{SD}$. The $p$ values are for comparison of the three genotypes (one-way ANOVA).

Table 3. $p Q C T$ measurements of cortical bone parameters according to COMT genotype

\begin{tabular}{|c|c|c|c|c|}
\hline Variable & $\operatorname{COMT}^{\mathrm{LL}}(n=85)$ & $\operatorname{COMT}^{\mathrm{HL}}(n=118)$ & $\operatorname{COMT}^{\mathrm{HH}}(n=43)$ & $p$ Value \\
\hline Cortical BMC (mg/mm) & $214 \pm 32$ & $207 \pm 34$ & $195 \pm 28$ & 0.008 \\
\hline Cortical vBMD $\left(\mathrm{mg} / \mathrm{cm}^{3}\right)$ & $1045 \pm 29$ & $1042 \pm 26$ & $1041 \pm 28$ & NS \\
\hline Cortical cross-sectional area $\left(\mathrm{mm}^{2}\right)$ & $204 \pm 29$ & $199 \pm 32$ & $187 \pm 25$ & 0.010 \\
\hline Endosteal circumference (mm) & $48 \pm 4$ & $46 \pm 4$ & $46 \pm 4$ & 0.022 \\
\hline Cortical thickness (mm) & $3.5 \pm 0.2$ & $3.4 \pm 0.3$ & $3.4 \pm 0.2$ & 0.006 \\
\hline Polar moment of inertia $(\mathrm{g} * \mathrm{~mm})$ & $2.1 \pm 0.6$ & $1.9 \pm 0.6$ & $1.8 \pm 0.5$ & 0.007 \\
\hline
\end{tabular}

Data are shown as mean $\pm \mathrm{SD}$. The $p$ values are for comparison of the three genotypes (one-way ANOVA).

Table 4. Hormone levels according to COMT genotype

\begin{tabular}{|c|c|c|c|c|}
\hline Variable & $\operatorname{COMT}^{\mathrm{LL}}(n=85)$ & $\operatorname{COMT}^{\mathrm{HL}}(n=118)$ & $\mathrm{COMT}^{\mathrm{HH}}(n=43)$ & $p$ Value \\
\hline Estradiol (pmol/L) & $113.2 \pm 59.7$ & $113.5 \pm 66.4$ & $91.1 \pm 48.4$ & NS \\
\hline SHBG (nmol/L) & $75.7 \pm 33.2$ & $83.6 \pm 32.9$ & $91.1 \pm 34.3$ & NS \\
\hline Free estradiol (pmol/L) & $2.5 \pm 1.4$ & $2.4 \pm 1.8$ & $1.7 \pm 1.1$ & 0.010 \\
\hline Free testosterone $(\mathrm{pmol} / \mathrm{L})$ & $3.3 \pm 3.5$ & $3.8 \pm 4.7$ & $2.8 \pm 2.8$ & NS \\
\hline $\mathrm{GH}(\mathrm{ng} / \mathrm{mL})$ & $2.3 \pm 4.2$ & $1.6 \pm 2.7$ & $1.1 \pm 2.0$ & NS \\
\hline IGF-1 (ng/mL) & $276 \pm 109$ & $232 \pm 100$ & $230 \pm 100$ & 0.029 \\
\hline
\end{tabular}

Data are shown as mean \pm SD. The $p$ values are for comparison of the three genotypes (one-way ANOVA).

COMT genotype was associated with BMC of the total body $(p=$ $0.001)$, femur neck $(p=0.008)$ and cortical bone of the tibia $(p=$ 0.002 ). When levels of free estradiol were included in the model, COMT genotype was no longer significantly associated with these parameters, suggesting that the COMT effect on BMC is exerted via elevated levels of free estradiol. COMT genotype was an important predictor of height $(p<0.001)$ and length of the tibial shaft $(p=0.001)$. When free estradiol was included in the linear regression model, COMT still retained some of its associations with height ( $p=0.024)$ and length of the tibial shaft $(p=0.021)$, suggesting that the COMT effect on longitudinal growth is exerted partly via elevated levels of estradiol and partly via mechanisms independent of estradiol.

Interaction between the effect of COMT genotype and muscle area on cortical BMC. We next used regression analyses to determine whether the association between COMT genotype and cortical BMC of the tibia could be mediated via a larger muscle mass, resulting in an increased mechanical load. The associations between cortical BMC of the tibia and COMT genotype vanished when cross sectional muscle area was included in the linear regression model ( $\mathrm{p}$ COMT $=0.192 ;$ p CSA $<0.001)$.

Tanner stage according to COMT genotype. At the initial screening for the study all 246 girls were in either Tanner stage 1 or 2 . When they returned for baseline measurements on average 3 mo later, 13 of them had progressed in to Tanner stage 3 . Interestingly, 8 of these 13 girls were $\mathrm{COMT}^{\mathrm{LL}}$ and 5 of them were $\mathrm{COMT}^{\mathrm{HL}}$, indicating that $\mathrm{COMT}^{\mathrm{L}}$ gives a more rapid onset of puberty. Girls with COMT ${ }^{\mathrm{LL}}$ were more likely to be in Tanner stage 2 or 3 than girls with $\mathrm{COMT}^{\mathrm{HH}}$ (Table 5). This difference is likely to be a consequence of their elevated levels of free estradiol, supported by the fact that the associations between COMT genotype and Tanner stage vanished when free estradiol was included in a linear regression model $(\mathrm{p}$ COMT $=0.183, \mathrm{p}$ free estradiol $<0.0001)$. 
Table 5. Tanner stage according to COMT genotype

\begin{tabular}{lcccc}
\hline Tanner stage & $\begin{array}{c}\mathrm{COMT}^{\mathrm{LL}} \\
(n=85)\end{array}$ & $\begin{array}{c}\mathrm{COMT}^{\mathrm{HL}} \\
(n=118)\end{array}$ & $\begin{array}{c}\mathrm{COMT}^{\mathrm{HH}} \\
(n=43)\end{array}$ & $\begin{array}{c}p \\
\text { Value }\end{array}$ \\
\hline $1(n=126)$ & $29.4 \%$ & $47.6 \%$ & $23.0 \%$ & \\
$2(n=107)$ & $37.4 \%$ & $49.5 \%$ & $13.1 \%$ & 0.003 \\
$3(n=13)$ & $61.5 \%$ & $38.5 \%$ & $0 \%$ & \\
\hline
\end{tabular}

Comparisons by Mantel-Haenszel test.

\section{DISCUSSION}

In this cohort of prepubertal/early pubertal caucasian girls, the COMT val158met polymorphism, resulting in altered serum levels of free estradiol, demonstrated a strong association with height, the difference between genotypes being $5.4 \mathrm{~cm}$. To our knowledge, this is the largest difference in height between genotypes ever reported for a single nucleotide polymorphism. This polymorphism was also associated with cortical bone dimensions and Tanner stage but not with trabecular volumetric $\mathrm{BMD}$. Our interpretation of these findings is that the less efficient degradation of estrogens caused by the methionine allele $\left(\mathrm{COMT}^{\mathrm{L}}\right)$ leads to elevated levels of biologically active estrogens, which in turn lead to earlier pubertal development and an increased skeletal size in pre/early pubertal girls.

DXA measurements of our study subjects showed a higher BMC and larger areas in $\mathrm{COMT}^{\mathrm{LL}}$ compared with $\mathrm{COMT}^{\mathrm{HH}}$, while aBMD did not differ between genotypes except for a minor difference in the spine. These findings suggest that the COMT val158met polymorphism is mainly associated with size and not mineralization. The DXA technique has limitations such as the influence of size on aBMD, this being especially problematic when growing children are measured. Therefore BMDvol of the lumbar spine was calculated, and no differences between genotypes were seen for this parameter. The higher spine aBMD, in the present study, might therefore very well be due to the larger size of the bones in the COMT ${ }^{\mathrm{LL}}$ girls, which is further supported by the pQCT findings that their volumetric cortical and trabecular BMDs were similar compared with other COMT genotypes. The pQCT measurements clarified that the associations, observed by the DXA, were caused by a difference in size of the bones while the "true" volumetric density was unaffected, and that the cortical but not the trabecular bone was influenced by the COMT polymorphism.

The larger cross sectional cortical area was due to a wider periosteal circumference, suggesting that the effect on cortical area was caused by an increased radial growth in COMT ${ }^{\mathrm{LL}}$ girls. These associations between COMT genotype and the outer dimensions of the skeleton might be of importance as bone size is a major determinant of bone strength (32). One may speculate that the reduced periosteal expansion seen in $\mathrm{COMT}^{\mathrm{HH}}$ individuals is caused by reduced serum levels of IGF-I. This notion is supported by the fact that the periosteal circumference completely failed to increase during sexual maturation in IGF-I KO mice (8). Moreover, our findings of a strong correlation between free estradiol and IGF-I which are in line with previous works finding a concomitant increase in estradiol and IGF-I levels during early puberty (33), further indicate that these effects originate from the COMT-affected free estradiol levels.

It is well known that the trabecular bone is very sensitive to endogenous estrogen levels in adult females (34). Therefore, one might have expected that the volumetric trabecular BMD should have been affected in the COMT ${ }^{\mathrm{LL}}$ genotype, which is associated with higher serum levels of estradiol. However, the trabecular vBMD was, in the present cohort including girls at early sexual maturation, unaffected by COMT genotype, which might indicate that, at this age, the skeletal growth is more sensitive than the trabecular $\mathrm{vBMD}$ to small alterations in estradiol levels.

One could speculate that the higher levels of estrogen, which are the result of a diminished degradation of estrogens in girls with $\mathrm{COMT}^{\mathrm{LL}}$, would be down-regulated by a feed back mechanism attenuating the differences between genotypes. However, during premenarche there is an auto-amplification of the hypothalamic-pituitary-gonadal axis rather than a negative feed back by estrogen on gonadotropins (35). COMT activity has been detected in the hypothalamus and the pituitary (36), as well as in the ovary (37), so it is also possible that local differences in COMT activity in these organs due to the val158met polymorphism could play yet unknown roles in the regulation of estradiol at these different levels.

Early puberty results in early closure of the epiphyseal growth plates. Thus, due to differences in pubertal onset, it could be expected that growth would cease earlier in COMT ${ }^{\mathrm{LL}}$ than in $\mathrm{COMT}^{\mathrm{HH}}$ girls. The latter would then as adults be taller due to a longer prepubertal growth period. However, the effects of maturational timing on adult stature are inconclusive with studies reporting slightly shorter adult stature (38) as well as others reporting a trend toward taller adult stature (39) in early maturing girls. Late maturing girls have been reported to have a lower peak height velocity (40) and girls with a large adult stature have been reported to start their pubertal growth spurt at the same age as girls with a small adult stature (41). Therefore the effect of COMT genotype on adult stature and skeleton can be determined only after cessation of the growth period.

Because of the known importance of estrogens for skeletal growth and BMD, many studies have been conducted to find genetic polymorphisms influencing the skeleton, in the genes coding for estrogen receptors (ERs). Results have sometimes been conflicting $(42,43)$, but a recent extensive meta-analysis found an association between the ER $\alpha$ polymorphism $X b a$ I and aBMD in women (44). Furthermore, the ER $\alpha$ polymorphism $P v u \mathrm{II}$ has also been reported to influence height in young males (45). Another approach is to investigate genes coding for enzymes involved in the synthesis and degradation of estrogens. The polymorphism we have studied is located in the gene coding for Catechol-O-methyltransferase (COMT). The first step in the degradation of estrogens is a hydroxylation mediated by various isoenzymes of the cytochrome P450 system. As a result several different hydroxylated metabolites, some of which are denoted CEs, appear. They retain some hormonal activity. CEs are to a large extent further metabolized by COMT. The resulting methylated metabolites do not bind to the estrogen receptors (25). The COMT val1158met polymor- 
phism has previously been shown to influence enzyme activity in vitro with a 3-4 fold decrease in activity for the enzyme encoded by the $\mathrm{COMT}^{\mathrm{L}}$ allele (26). Thus, the low activity COMT enzyme should theoretically increase the serum levels of estrogens and $\mathrm{CE}$, which is supported by the present in vivo finding that $\mathrm{COMT}^{\mathrm{LL}}$ individuals have increased serum levels of estradiol. Furthermore, we have previously shown that middle aged men with $\mathrm{COMT}^{\mathrm{LL}}$ have higher serum levels of estradiol than men with other genotypes (27), and it has also been reported that serum levels of estradiol $3 \mathrm{~h}$ after a single dose of estradiol valerate were higher in post menopausal women with $\mathrm{COMT}^{\mathrm{LL}}$ than in women with $\mathrm{COMT}^{\mathrm{HH}}$ (46). Thus, these three recent in vivo data indicate that $\mathrm{COMT}^{\mathrm{LL}}$ individuals have an affected degradation of both endogenously synthesized estradiol and exogenously delivered estradiol. Interestingly, regression analyses indicated that the effect of the COMT polymorphism on cortical bone dimensions and linear growth are mediated via a regulation of serum levels of free estradiol. As the serum levels of free estradiol were elevated in girls with $\mathrm{COMT}^{\mathrm{LL}}$, the finding of a more rapid onset of estrogen-regulated pubertal development (Tanner stage), in these subjects, was expected.

Cross sectional muscle area of the lower leg and whole body lean mass were larger in $\mathrm{COMT}^{\mathrm{LL}}$ while there only was a tendency of an association with fat mass. Estrogen has, in some previous studies, been shown to exert anabolic effects on muscle mass $(47,48)$, suggesting that the effect on lean mass and muscle in $\mathrm{COMT}^{\mathrm{LL}}$ might also be a direct consequence of the elevated levels of estradiol.

In summary we have, shown that in our cohort of prepubertal/early pubertal caucasian girls the COMT val158met polymorphism is strongly associated with height and cortical bone dimensions. COMT genotype is also associated with serum levels of free estradiol, Tanner stage and IGF-I. We propose that a low activity COMT genotype results in higher free estradiol levels and an earlier pubertal development, which in turn results in increased skeletal growth in pre/early pubertal girls.

Acknowledgments. The authors are grateful to Lotta Uggla and Erkki Helkala for excellent technical support.

\section{REFERENCES}

1. Johnston CC Jr, Slemenda CW 1994 Peak bone mass, bone loss and risk of fracture. Osteoporos Int 4(suppl 1):43-45

2. Seeman E, Tsalamandris C, Formica C, Hopper JL, McKay J 1994 Reduced femoral neck bone density in the daughters of women with hip fractures: the role of low peak bone density in the pathogenesis of osteoporosis. J Bone Miner Res 9:739-743

3. Harris M, Nguyen TV, Howard GM, Kelly PJ, Eisman JA 1998 Genetic and environmental correlations between bone formation and bone mineral density: a twin study. Bone 22:141-145

4. Eisman JA 1999 Genetics of osteoporosis. Endocr Rev 20:788-804

5. Saggese G, Baroncelli GI, Bertelloni S 2002 Puberty and bone development. Best Pract Res Clin Endocrinol Metab 16:53-64

6. Heaney RP, Abrams S, Dawson-Hughes B, Looker A, Marcus R, Matkovic V, Weaver C 2000 Peak bone mass. Osteoporos Int 11:985-1009

7. Robson H, Siebler T, Shalet SM, Williams GR 2002 Interactions between GH, IGF-I, glucocorticoids, and thyroid hormones during skeletal growth. Pediatr Res 52:137147

8. Mohan S, Richman C, Guo R, Amaar Y, Donahue LR, Wergedal J, Baylink DJ 2003 Insulin-like growth factor regulates peak bone mineral density in mice by both growth hormone-dependent and -independent mechanisms. Endocrinology 144:929-936

9. Ohlsson C, Bengtsson BA, Isaksson OG, Andreassen TT, Slootweg MC 1998 Growth hormone and bone. Endocr Rev 19:55-79
10. Libanati C, Baylink DJ, Lois-Wenzel E, Srinvasan N, Mohan S 1999 Studies on the potential mediators of skeletal changes occurring during puberty in girls. J Clin Endocrinol Metab 84:2807-2814

11. Richman C, Kutilek S, Miyakoshi N, Srivastava AK, Beamer WG, Donahue LR, Rosen CJ, Wergedal JE, Baylink DJ, Mohan S 2001 Postnatal and pubertal skeletal changes contribute predominantly to the differences in peak bone density between $\mathrm{C} 3 \mathrm{H} / \mathrm{HeJ}$ and C57BL/6J mice. J Bone Miner Res 16:386-397

12. Smith EP, Boyd J, Frank GR, Takahashi H, Cohen RM, Specker B, Williams TC, Lubahn DB, Korach KS 1994 Estrogen resistance caused by a mutation in the estrogen-receptor gene in a man. N Engl J Med 331:1056-1061

13. Carani C, Qin K, Simoni M, Faustini-Fustini M, Serpente S, Boyd J, Korach KS, Simpson ER 1997 Effect of testosterone and estradiol in a man with aromatase deficiency. N Engl J Med 337:91-95

14. Vidal O, Lindberg MK, Hollberg K, Baylink DJ, Andersson G, Lubahn DB, Mohan S, Gustafsson JA, Ohlsson C 2000 Estrogen receptor specificity in the regulation of skeletal growth and maturation in male mice. Proc Natl Acad Sci U S A 97:54745479

15. Windahl SH, Vidal O, Andersson G, Gustafsson JA, Ohlsson C 1999 Increased cortical bone mineral content but unchanged trabecular bone mineral density in female ERbeta(-/-) mice. J Clin Invest 104:895-901

16. Mauras N, Rogol AD, Veldhuis JD 1989 Specific, time-dependent actions of lowdose ethinyl estradiol administration on the episodic release of growth hormone, follicle-stimulating hormone, and luteinizing hormone in prepubertal girls with Turner's syndrome. J Clin Endocrinol Metab 69:1053-1058

17. Wennink JM, Delemarre-van de Waal HA, Schoemaker R, Blaauw G, van den Braken C, Schoemaker J 1991 Growth hormone secretion patterns in relation to LH and estradiol secretion throughout normal female puberty. Acta Endocrinol (Copenh) 124:129-135

18. Sjogren K, Liu JL, Blad K, Skrtic S, Vidal O, Wallenius V, LeRoith D, Tornell J, Isaksson OG, Jansson JO, Ohlsson C 1999 Liver-derived insulin-like growth factor I (IGF-I) is the principal source of IGF-I in blood but is not required for postnatal body growth in mice. Proc Natl Acad Sci U S A 96:7088-7092

19. Isaksson OG, Lindahl A, Nilsson A, Isgaard J 1987 Mechanism of the stimulatory effect of growth hormone on longitudinal bone growth. Endocr Rev 8:426-438

20. Brameld JM, Atkinson JL, Saunders JC, Pell JM, Buttery PJ, Gilmour RS 1996 Effects of growth hormone administration and dietary protein intake on insulin-like growth factor I and growth hormone receptor mRNA Expression in porcine liver, skeletal muscle, and adipose tissue. J Anim Sci 74:1832-1841

21. Woods KA, Camacho-Hubner C, Savage MO, Clark AJ 1996 Intrauterine growth retardation and postnatal growth failure associated with deletion of the insulin-like growth factor I gene. N Engl J Med 335:1363-1367

22. Kusec V, Virdi AS, Prince R, Triffitt JT 1998 Localization of estrogen receptor-alpha in human and rabbit skeletal tissues. J Clin Endocrinol Metab 83:2421-2428

23. Nilsson LO, Boman A, Savendahl L, Grigelioniene G, Ohlsson C, Ritzen EM, Wroblewski J 1999 Demonstration of estrogen receptor-beta immunoreactivity in human growth plate cartilage. J Clin Endocrinol Metab 84:370-373

24. Vidal O, Kindblom LG, Ohlsson C 1999 Expression and localization of estrogen receptor-beta in murine and human bone. J Bone Miner Res 14:923-929

25. Zhu BT, Conney AH 1998 Functional role of estrogen metabolism in target cells: review and perspectives. Carcinogenesis 19:1-27

26. Lachman HM, Papolos DF, Saito T, Yu YM, Szumlanski CL, Weinshilboum RM 1996 Human catechol-O-methyltransferase pharmacogenetics: description of a functional polymorphism and its potential application to neuropsychiatric disorders. Pharmacogenetics 6:243-250

27. Eriksson AL, Skrtic S, Niklason A, Hulten LM, Wiklund O, Hedner T, Ohlsson C 2004 Association between the low activity genotype of catechol-O-methyltransferase and myocardial infarction in a hypertensive population. Eur Heart J 25:386-391

28. Suuriniemi M, Mahonen A, Kovanen V, Alen M, Cheng S 2003 Relation of PvuII site polymorphism in the COL1A2 gene to the risk of fractures in prepubertal Finnish girls. Physiol Genomics 14:217-224

29. Kroger H, Kotaniemi A, Vainio P, Alhava E 1992 Bone densitometry of the spine and femur in children by dual-energy x-ray absorptiometry. Bone Miner 17:75-85

30. Ankarberg C, Norjavaara E 1999 Diurnal rhythm of testosterone secretion before and throughout puberty in healthy girls: correlation with 17beta-estradiol and dehydroepiandrosterone sulfate. J Clin Endocrinol Metab 84:975-984

31. Howell WM, Jobs M, Gyllensten U, Brookes AJ 1999 Dynamic allele-specific hybridization. A new method for scoring single nucleotide polymorphisms. Nat Biotechnol 17:87-88

32. Seeman E 2003 Periosteal bone formation - a neglected determinant of bone strength N Engl J Med 349:320-323

33. Blogowska A, Rzepka-Gorska I, Krzyzanowska-Swiniarska B 2003 Growth hormone, IGF-1, insulin, SHBG, and estradiol levels in girls before menarche. Arch Gynecol Obstet 268:293-296

34. Riggs BL, Khosla S, Melton LJ 3rd 2002 Sex steroids and the construction and conservation of the adult skeleton. Endocr Rev 23:279-302

35. Legro RS, Lin HM, Demers LM, Lloyd T 2000 Rapid maturation of the reproductive axis during perimenarche independent of body composition. J Clin Endocrinol Metab 85:1021-1025

36. Masuda M, Tsunoda M, Imai K 2003 High-performance liquid chromatographyfluorescent assay of catechol-O-methyltransferase activity in rat brain. Anal Bioanal Chem 376:1069-1073

37. Lee BC, Cha K, Avraham S, Avraham HK 2004 Microarray analysis of differentially expressed genes associated with human ovarian cancer. Int J Oncol 24:847-851

38. Garn SM, LaVelle M, Rosenberg KR, Hawthorne VM 1986 Maturational timing as a factor in female fatness and obesity. Am J Clin Nutr 43:879-883 
39. Hagg U, Taranger J 1992 Pubertal growth and maturity pattern in early and late maturers. A prospective longitudinal study of Swedish urban children. Swed Dent J 16:199-209

40. Iuliano-Burns S, Mirwald RL, Bailey DA 2001 Timing and magnitude of peak height velocity and peak tissue velocities for early, average, and late maturing boys and girls. Am J Human Biol 13:1-8

41. Gasser T, Sheehy A, Molinari L, Largo RH 2001 Growth processes leading to a large or small adult size. Ann Hum Biol 28:319-327

42. Langdahl BL, Lokke E, Carstens M, Stenkjaer LL, Eriksen EF 2000 A TA repeat polymorphism in the estrogen receptor gene is associated with osteoporotic fractures but polymorphisms in the first exon and intron are not. J Bone Miner Res 15:2222 2230

43. Yamada Y, Ando F, Niino N, Ohta S, Shimokata H 2002 Association of polymorphisms of the estrogen receptor alpha gene with bone mineral density of the femoral neck in elderly Japanese women. J Mol Med 80:452-460

44. Ioannidis JP, Stavrou I, Trikalinos TA, Zois C, Brandi ML, Gennari L, Albagha O, Ralston SH, Tsatsoulis A; ER-alpha Genetics Meta-Analysis 2002 Association of polymorphisms of the estrogen receptor alpha gene with bone mineral density and fracture risk in women: a meta-analysis. J Bone Miner Res 17:20482060

45. Lorentzon M, Lorentzon R, Backstrom T, Nordstrom P 1999 Estrogen receptor gene polymorphism, but not estradiol levels, is related to bone density in healthy adolescent boys: a cross-sectional and longitudinal study. J Clin Endocrinol Metab 84:45974601

46. Worda C, Sator MO, Schneeberger C, Jantschev T, Ferlitsch K, Huber JC 2003 Influence of the catechol-O-methyltransferase (COMT) codon 158 polymorphism on estrogen levels in women. Hum Reprod 18:262-266

47. Vandenput L, Boonen S, Van Herck E, Swinnen JV, Bouillon R, Vanderschueren D 2002 Evidence from the aged orchidectomized male rat model that 17 beta-estradiol is a more effective bone-sparing and anabolic agent than 5alpha-dihydrotestosterone. J Bone Miner Res 17:2080-2086

48. Rumsey TS, Tyrrell HF, Dinius DA, Moe PW, Cross HR1981 Effect of diethylstilbestrol on tissue gain and carcass merit of feedlot beef steers. J Anim Sci 53:589-600 